\title{
A IMPORTÂNCIA DO INPUT E OUTPUT DOS PAIS EM CRIANÇAS BILINGUES
}

\author{
Anabela Fernandes Custódio \\ Universidad de Extremadura \\ anabelacustodio@gmail.com \\ Inmaculada Sanchez Casado \\ Universidad de Extremadura \\ iscasado@unex.es
}

Recepción Artículo: 22 octubre 2021

Admisión Evaluación: 22 octubre 2021

Informe Evaluador 1: 23 octubre 2021

Informe Evaluador 2: 24 octubre 2021

Aprobación Publicación: 24 octubre 2021

\section{RESUMO}

A quantidade e qualidade de input recebido dos pais é fundamental para que as crianças produzam output, elas recebem informação, processam a informação recebida e produzem conhecimento. Lundquist-Mog e Widlok (2015) mencionam a investigadora Gabriele Kniffka (2013) que explica a aprendizagem de uma língua referindo que 0 cérebro da criança, ao contactar com uma segunda língua, pelos quatro anos de idade, compartimenta e absorve 0 input de uma forma criativa, baseando-se nos conhecimentos já adquiridos incluindo os saberes da sua língua materna, define generalizações de forma que vai juntar o novo conhecimento adquirido ao que já aprendeu. A generalização ajuda a criança a desenvolver novas regras gramaticais ou palavras sem sentido tentando arranjar novas formas de se exprimir. A criança serve-se desta estratégia para fazer experimentações como formular ideias e deve ser motivada a falar recebendo da parte do professor o input correto.

Para que a criança desenvolva um repertório numa língua estrangeira que the conceda as habilidades linguísticas suficientes para se expressar é necessário receber uma grande quantidade de inputs. Esta condição será primordial para que a criança progrida na aprendizagem. Destacam as autoras Lundquist-Mog e Widlok (2015), que 0 facto de a criança ouvir primeiro leva a crer que quantos mais impulsos auditivos receber, mais será capaz de imitar e de reproduzir. Este estudo desenvolve-se com os progenitores de 31 crianças e tem como objetivo avaliar a importância do input e output dos pais em crianças bilingues. Os progenitores responderam a um questionário sociolinguístico cuja recolha de dados informativos serviu de base para estudar a quantidade de input linguístico que os falantes bilingues recebem em cada uma das suas línguas, assim como a diversidade e a qualidade das fontes de exposição linguística a que têm acesso e que são considerados como fatores intervenientes no processo de aquisição bilingue.

Palavras chave: segunda língua dos pais; input; output; progenitores 


\section{A IMPORTÂNCIA DO INPUT E OUTPUT DOS PAIS EM CRIANÇAS BILINGUES}

\section{ABSTRACT}

The importance of parental input and output in bilingual children. The quantity and quality of input received from parents is fundamental for children to produce output, they receive information, process the information received and produce knowledge. Lundquist-Mog and Widlok (2015) mention the researcher Gabriele Kniffka (2013) who explains the learning of a language referring that the child's brain, when contacting a second language, by the age of four, compartments and absorbs the input of a In a creative way, based on the knowledge already acquired including the knowledge of your mother tongue, it defines generalizations in a way that will add the new knowledge acquired to what you have already learned. Generalization helps the child to develop new grammatical rules or nonsense words trying to find new ways to express themselves. The child uses this strategy to experiment with formulating ideas and must be motivated to speak, receiving the correct input from the teacher.

In order for a child to develop a repertoire in a foreign language that gives him sufficient linguistic skills to express himself, he needs to receive a great deal of input. This condition will be essential for the child to progress in learning. The authors Lundquist-Mog and Widlok (2015) emphasize that the fact that the child listens first leads to the belief that the more auditory impulses they receive, the more they will be able to imitate and reproduce. This study is carried out with the parents of 31 children and aims to assess the importance of parental input and output in bilingual children. Parents answered a sociolinguistic questionnaire whose collection of informative data served as the basis for studying the amount of linguistic input that bilingual speakers receive in each of their languages, as well as the diversity and quality of the sources of linguistic exposure to which they have access. and which are considered as intervening factors in the bilingual acquisition process.

Keywords: parents`second language; input; output; parents

\section{INTRODUCCIÓN}

0 tema bilinguismo está quase sempre associado a famílias que por necessidades várias são obrigadas a trocar o seu país por outro cuja língua e cultura são desconhecidas. 0 desafio é enorme, mas motivador. 0 crescimento das populações gera a necessidade de conhecer várias línguas. Atualmente, muitos são os que anseiam por dominar mais do que uma língua, isto é, de se tornarem bilingues. Cada vez mais os pais procuram desenvolver esta competência nos filhos (Abdelilah-Bauer, 2012). Grosjean (2021) defende que orientar famílias bilingues é uma tarefa árdua pois cada família apresenta características diferentes ditadas pelas línguas maternas e se há estratégias que são um sucesso perto de umas famílias e são um fracasso perto de outras.

0 autor argumenta que a maior parte das crianças adquire as suas línguas naturalmente se elas viverem numa família ou num meio social que requere o uso de duas ou mais línguas. Numa situação com estas características o planeamento pode não ser necessário porque inúmeros de fatores são favoráveis ao uso das línguas e estas crianças tornam-se bilingues de forma natural. De uma forma geral, afirma 0 autor, o plano dos pais que querem transformar os seus filhos em crianças bilingues adotam a estratégia "uma pessoa-uma língua" (cada pai fala exclusivamente a sua língua com a criança); ou a língua minoritária em casa e a outra em sociedade e por aí adiante. Segundo 0 autor estas estratégias têm vantagens e inconvenientes. Na estratégia "uma pessoa-uma língua", a criança torna-se bilingue porque cada pai (ou mãe) fala com ela usando exclusivamente a sua língua dominante. 0 problema situa-se nas relações da criança fora de casa. A língua minoritária pode sofrer com a falta de uso por parte da criança e dá o exemplo da língua chinesa nos Estados Unidos, onde a língua mais forte é que é a usada. A estratégia em que uma língua é usada em casa e a outra é usada em sociedade considera-se de sucesso, mas um dos pais tem de estar de acordo em falar a sua língua em casa com a criança.

Para desenvolver a linguagem, as crianças requerem uma certa quantidade de input em diferentes situações, vindo dos membros da família, dos amigos e outros. Como descrito por Grosjean (2021), investigações sobre 0 tema demonstraram que as crianças necessitam da presença de uma pessoa para interagir com elas para que possam adquirir a linguagem e as suas características fonéticas e isto, não pode ser feito simplesmente observando a televisão ou ouvindo música. 0 input deve ser recebido também através do discurso familiar e neste caso contém "code-swichtches" (alternâncias) e "borrowings" (apropriação de palavras) o que acontece com muita fre- 
quência num bilingue que emprega linguagem familiar. 0 input deve ser recebido através de um discurso monolingue como o que é falado pelos membros da família que não sabem falar outra língua.

\section{OBJETIVOS DE LA INVESTIGACIÓN}

0 objetivo geral do estudo é determinar a importância do input e output dos pais em crianças bilingues. Os objetivos específicos definidos para este estudo são: identificar de que forma a quantidade e a qualidade do input dos pais interferem na aprendizagem de uma língua; compreender que papel desempenha a família na educação bilingue; verificar se a escolaridade dos pais influencia os resultados obtidos nos testes e; averiguar se o contexto familiar pode influenciar o desenvolvimento cognitivo na aprendizagem de uma segunda língua.

\section{MUESTRA Y/O PARTICIPANTES}

A amostra é formada pelos progenitores de 31 crianças divididas em dois grupos, $A$ e $B$, designados por $G A$ e GB. 0 grupo A - 4 anos e 5 anos ( $n=19)$ e 0 grupo B - 4 anos e 5 anos ( $n=12)$. Para realizar a caracterização dos pais foi aplicado um questionário sociolinguístico que contribui para conhecer melhor o meio social em que se movem as famílias e os participantes no estudo e ajuda a organizar, normalizar e controlar os dados considerados importantes para a caracterização dos sujeitos referidos anteriormente. É feita uma caracterização dos progenitores relativamente à nacionalidade, nível de escolaridade, ao país de origem, bem como a análise da língua falada pelos mesmos em contexto familiar.

\section{METODOLOGÍA Y/O INSTRUMENTOS UTILIZADOS}

Foi aplicado um questionário parental pormenorizado (Correia, 2017), com questões em forma de pergunta fechada. Este questionário permitiu não só a recolha de dados biográficos sobre os progenitores, como também de informações sobre as suas experiências sociolinguísticas dentro e fora do contexto doméstico que se revelam essenciais para se determinar, por exemplo, a quantidade de input linguístico que os falantes bilingues recebem em cada uma das suas línguas, assim como a diversidade e a qualidade das fontes de exposição linguística a que têm acesso (interlocutores nativos/não nativos; contexto doméstico/escolar; entre outros), que são considerados como fatores intervenientes no processo de aquisição bilingue.

Segundo Marôco (2007), a operacionalização de técnicas mais ou menos padronizadas como por exemplo o inquérito por questionário, permite realizar uma análise quantitativa das informações recolhidas de modo a possibilitar generalizações.

Com base em Correia (2017) e Correia e Flores (2017) e nos dados informativos do questionário preenchido pelos progenitores dos alunos que participaram no estudo, calculou-se: (1) a quantidade de progenitores falantes do português, através da soma do número de progenitores que têm o português como língua materna, variando os resultados dicotomicamente entre ambos e mãe ou pai; (2) a quantidade de exposição linguística à língua materna em contexto doméstico através da soma da quantidade de input, recebido de cada progenitor, cujo valor pode variar entre 0 mínimo de zero e o máximo de 100, resultando numa escala de zero a 200; (3) a quantidade de exposição linguística à língua materna em contexto doméstico através da soma da quantidade de output, recebido de cada progenitor, utilizando-se uma escala de medição idêntica à anterior; (4) a quantidade de parceiros conversacionais falantes nativos do português em contexto de emigração (avós), através da soma do número de locutores nativos que contactam assiduamente em português com os bilingues; e (5) a quantidade de atividades de lazer (televisão, música, internet, entre outras) em que a língua portuguesa é utilizada, através da soma do número de atividades lúdicas em que as crianças bilingues participam habitualmente, aplicando a língua portuguesa.

Os dados fornecidos pelo questionário permitiram averiguar se variáveis como (6) a existência de irmãos mais velhos e (7) a idade dos bilingues, no momento da recolha de dados, têm influência no desenvolvimento cognitivo das crianças bilingues. 


\section{A IMPORTÂNCIA DO INPUT E OUTPUT DOS PAIS EM CRIANÇAS BILINGUES}

\section{RESULTADOS ALCANZADOS}

Para caracterizar as famílias dos falantes bilingues ( $n=31$ ) participantes no estudo GA ( $n=19)$ e GB $(n=12)$ foram recolhidas e analisadas as informações que os progenitores forneceram no questionário sociolinguístico. Quanto às nacionalidades da constituição familiar, há 17 pais de nacionalidade francesa e 14 de nacionalidade portuguesa. Quanto às mães, 15 são de nacionalidade francesa e 16 de nacionalidade portuguesa.

Verifica-se assim, que a maioria dos falantes $(n=22)$ é de famílias que em casa partilham as duas línguas, ou seja, o português e o francês, sendo que, seis falam frequentemente o português. Por sua vez, há quatro famílias em que o francês aparece como língua maioritária. Relativamente ao nível de escolaridade dos progenitores situase entre 0 2. ํㅜㄷㅇ e o nível universitário. As habilitações académicas a nível universitário são em maior número no $\mathrm{GA}$ que no $\mathrm{GB}$.

\section{DISCUSIÓN}

As análises estatísticas revelam que relativamente à língua falada pelos progenitores, verifica-se no grupo $\mathrm{A}$ (4 anos) que 42,9\% têm ambos os pais falantes de português, 42,9\% apenas a mãe e 14,3\% apenas o pai; no grupo A (5 anos) a maioria tem ambos os pais falantes de português ( $75 \%$ e e $25 \%$ apenas o pai. No grupo B (4 anos) uma grande percentagem ou tem apenas o pai falante de português (37,5\%) ou apenas a mãe $(37,5 \%)$; somente $25 \%$ têm ambos os pais falantes de português. No grupo B (5 anos) metade tem ambos os pais falantes de português e a outra metade apenas a mãe. Relativamente ao país de origem dos pais dos falantes bilingues, Portugal/França são os mais referidos.

A escolaridade do pai e da mãe é elevada nos grupos $A$ e $B$, havendo uma predominância do ensino universitário.

Quanto à existência de irmãos mais velhos, no grupo $\mathrm{A}$ (4 anos) a maioria não tem irmãos mais velhos (57,1\%), no grupo $A$ ( 5 anos), metade tem irmãos mais velhos e a outra metade não e no grupo $B$, quer nas crianças de quatro quer nas crianças de cinco anos, a maioria (62,5\%), ou todos têm irmãos mais velhos.

No grupo A existe uma média mais elevada de input dos pais ( 4 anos $=117,86 / 5$ anos $=129,17$ ) do que no grupo $B(4$ anos $=43,75 / 5$ anos $=87,50$ ), é também no grupo $A$ que existe uma maior quantidade de parceiros conversacionais falantes de português ( 4 anos $=4,14 / 5$ anos $=3,33$ ) do que no grupo $B(4$ anos $=0,88 / 5$ anos $=$ $1,75)$.

Quanto à média de output dos pais é 0 grupo $A / 5$ anos que revela a média mais alta $(120,83)$, seguida do grupo $\mathrm{B} / 5$ anos $(75,0)$, do grupo $\mathrm{A} / 4$ anos $(67,86)$ e em último, com a média mais baixa 0 grupo B/4 anos $(18,75)$.

Quanto à quantidade de outras fontes de input as médias dos dois grupos são relativamente semelhantes (oscilam entre 4,33 e 5,25).

\section{CONCLUSIONES}

Para avaliar a influência que a quantidade de exposição linguística, input-pais, implicou no desenvolvimento cognitivo das crianças do GA - quatro anos ( $n=7)$ utilizaram-se os dados recolhidos no questionário sociolinguístico em correlação com os dados estatísticos.

A quantidade de input-pais varia entre 0 valor mínimo 25 e 0 máximo de $150(M=117,86 ; D P=42,61)$. Relativamente ao output-pais, 0 valor varia entre 0 valor mínimo 0 e o máximo de $150(67,86$; $D P=57,22)$.

Relativamente à quantidade de input linguístico que receberam dos pais, apenas duas crianças $(n=2)$ revelaram um bom desenvolvimento cognitivo. As outras cinco crianças $(n=5)$ revelaram um desempenho cognitivo inferior.

0 papel do input relacionado com a qualidade e a quantidade de exposição linguística pode influenciar 0 desenvolvimento cognitivo. A qualidade prende-se com a escolaridade dos progenitores (nível universitário - 5 pais e 3 mães). A quantidade pode estar relacionada com outras fontes de input que variam entre uma e quatro $(\mathrm{M}=4,71 ; \mathrm{DP}=, 95)$. 
Os irmãos mais velhos são fatores preditivos que ajudam a desenvolver o desempenho lexical nos falantes bilingues que por sua vez tem repercussões positivas no desenvolvimento cognitivo (Boehm, 2012).

No caso deste grupo, apenas três crianças têm irmãos mais velhos $(n=3=42,9 \%)$. Os restantes ( $n=4=$ $58,1 \%$ ) não têm irmãos mais velhos. Os resultados no teste de conceitos variam entre $0 \%$ e $92 \%$.

Para avaliar a influência que a quantidade de exposição linguística, input-pais, implicou no desenvolvimento cognitivo das crianças do GA - 5 anos ( $n=12$ ) seguiu-se o mesmo processo anterior utilizando os dados recoIhidos no questionário sociolinguístico em correlação com os dados estatísticos.

A quantidade de input-pais varia entre 0 valor mínimo 25 e 0 máximo de $200(M=129,17 ; D P=52,04)$. Relativamente ao output-pais o valor varia entre o valor mínimo ,00 e o máximo de $200(\mathrm{M}=120,83 ; \mathrm{DP}=61,08)$.

As crianças ( $n=2$ ) que revelam menor desenvolvimento cognitivo, recebem dos pais $25 \%$ e $100 \%$ de input e 0\% e 100\% de output respetivamente, não convivem com outras pessoas falantes do português o que pode influenciar negativamente 0 seu desenvolvimento cognitivo. Apenas recebem mais algum input dos medias (música, televisão, livros).

Uma criança $(n=1)$ recebe apenas $100 \%$ de input e $50 \%$ de output dos pais, mas tem irmãos mais velhos e fala com os avós paternos. As restantes três crianças $(n=3)$ recebem input e output dos pais de $200 \%$; $175 \%$; $150 \%$.

Os resultados estão em correlação com a quantidade de input e a quantidade de output recebidas. Neste grupo de crianças, apenas duas $(\mathrm{n}=2)$ revelam um bom desenvolvimento cognitivo.

A quantidade de input e output recebida dos pais é de $75 \%$ e $200 \%$ respetivamente. Variáveis como a qualidade do input recebido, a quantidade de parceiros conversacionais pode ter um impacto positivo no desenvolvimento cognitivo das crianças.

Há ainda que referir algumas crianças que apresentam um desenvolvimento cognitivo fraco. Uma das crianças recebe dos pais $125 \%$ de input e $100 \%$ de output; outra $100 \%$ tanto de input como de output e ainda outra, que recebe dos pais $150 \%$ tanto de input como de output.

0 papel do input relacionado com a qualidade e a quantidade de exposição linguística pode influenciar 0 desenvolvimento cognitivo. A qualidade prende-se com a escolaridade dos progenitores (nível universitário -10 pais $(83,3 \%)$ e 10 mães $(83,3 \%))$. A quantidade pode estar relacionada com outras fontes de Input que variam entre duas e cinco $(M=4,33 ; D P=, 98)$.

Os irmãos mais velhos são fatores preditivos que ajudam a desenvolver 0 desempenho lexical nos falantes bilingues que por sua vez tem repercussões positivas no desenvolvimento cognitivo (Boehm, 2012).

No caso deste grupo, seis crianças têm irmãos mais velhos ( $n=6=50 \%$ ). Os restantes ( $n=6=50 \%$ ) não têm irmãos mais velhos. Os resultados no teste de conceitos verificaram-se entre os $6 \%$ e os $98 \%$.

Seguiu-se o mesmo procedimento para avaliar a influência que a quantidade de exposição linguística, inputpais, implicou no desenvolvimento cognitivo das crianças do $\mathrm{GB}-4$ anos $(\mathrm{n}=8)$ utilizou-se os dados recolhidos no questionário sociolinguístico em correlação com os dados estatísticos. A quantidade de input-pais varia entre 0 valor mínimo ,00 e o máximo de $150(M=43,75 ; D P=66,48)$.

Relativamente ao output-pais, o valor varia entre 0 valor mínimo, 00 e 0 máximo de $50(M=18,75 ; D P=$ $22,16)$. Relativamente à quantidade de input-pais duas crianças, receberam muito pouco input dos pais $(25 \%)$. Duas crianças $(n=2)$ receberam $150 \%$ de input cada.

Quanto a quatro crianças ( $n=4)$ não há nenhuma informação sobre o input e output que receberam dos pais ou de outras fontes. No que respeita à informação sobre output de duas crianças $(n=2)$ uma teve $25 \%$; e a outra $0 \%$. Duas outras crianças ( $n=2)$ registaram $50 \%$ de output com os pais.

Cinco destas crianças têm irmãos mais velhos. Os resultados no teste de conceitos foram muito fracos, variaram entre 27\% e 69\%. Para avaliar a influência que a quantidade de exposição linguística, input-pais, implicou no desenvolvimento cognitivo das crianças do grupo $B-5$ anos $(n=4)$ utilizou-se mais uma vez os dados recoIhidos no questionário sociolinguístico em correlação com os dados estatísticos. 


\section{A IMPORTÂNCIA DO INPUT E OUTPUT DOS PAIS EM CRIANÇAS BILINGUES}

A quantidade de input-pais varia entre 0 valor mínimo 25 e 0 máximo de $175(M=87,50 ; D P=66,14)$. Relativamente ao output-pais, o valor varia entre 0 valor mínimo 25 e o máximo de $175(75,00 ; D P=70,71)$.

Relativamente à quantidade de input linguístico que receberam dos pais, uma criança foi a que recebeu menos input (25\%) e a que revelou melhor desenvolvimento cognitivo. A qualidade de input e 0 facto de ter irmãos mais velhos podem ter contribuído para o desenvolvimento cognitivo desta criança.

As outras duas crianças $(n=2)$ também revelaram um bom desenvolvimento cognitivo, além de receberem uma maior quantidade de input dos pais, também têm irmãos mais velhos.

A última criança, apesar dos pais terem formação universitária e a mãe ser falante do português, apresenta um desenvolvimento cognitivo insuficiente possivelmente porque apenas recebeu $50 \%$ de input da mãe e teve uma produção linguística muito reduzida. 0 papel do input relacionado com a qualidade e a quantidade de exposição linguística pode influenciar o desenvolvimento cognitivo.

A qualidade prende-se com a escolaridade dos progenitores (nível universitário -3 pais (75\%) e 3 mães $(75 \%)$. A quantidade pode estar relacionada com outras fontes de input que variam entre três e quatro $(M=4,71$; $\mathrm{DP}=, 95)$.

Os irmãos mais velhos são fatores preditivos que ajudam a desenvolver o desempenho lexical nos falantes bilingues que por sua vez tem repercussões positivas no desenvolvimento cognitivo (Boehm, 2012). No caso deste grupo, todas as crianças têm irmãos mais velhos ( $n=4=42,9 \%)$. 0 resultado no teste de conceitos está compreendido entre $42 \%$ e $100 \%$.

A partir destes dados propõe-se que 0 apoio familiar parece ser essencial para a aprendizagem de uma segunda língua. Baker e Wright (2021) destacam que uma atitude positiva e motivação são segundo Al-Hoorie e MacIntyre (2020) necessárias para as crianças que iniciam a aprendizagem de uma segunda língua.

A motivação torna-se ainda mais importante para sustentar o longo processo de obtenção de um nível suficiente de competência comunicativa nessa nova língua. Os autores acrescentam que Lamb et al. (2019, pp. 4-5) referem que as crianças devem ultrapassar desafios que dependem das suas capacidades linguísticas, das suas vivências sociais entre outros, para terem sucesso na aprendizagem linguística.

Baker e Wright (2021) argumentam que não é fácil julgar os resultados obtidos pelas crianças porque uma educação bilingue eficaz depende de muitos fatores tais como as crianças, os professores, a comunidade, a escola e 0 tipo de programa com o qual as crianças aprendem. Estes estudiosos defendem que fora da escola é a família e a comunidade que devem assegurar todos os fatores que contribuem para o equilíbrio na vida da criança. Baker e Wright (2021) argumentam que 0 ambiente social, cultural e político em que a escola está inserida pode afetar a educação de crianças de línguas minoritárias.

Nestes resultados observa-se que algumas crianças recebem pouco input dos pais a que se adiciona o input dos media como televisão, música e filmes. Como argumenta Grosjean (2021), as crianças necessitam de uma certa quantidade de input para aprender uma língua. É fundamental que as crianças interajam em várias situações com familiares, amigos e comunidade porque 0 input recebido dos média acima referidos não é suficiente para a aprendizagem de uma língua. Como propõem os estudos de Piaget (1952) e Vygotsky (1934), variáveis como o input e output dos pais; os parceiros conversacionais como os avós e irmãos mais velhos e os amigos interferem no desenvolvimento cognitivo da criança porque ela vai procurar informações do meio que a envolve para construir o seu próprio conhecimento.

\section{REFERENCIAS BIBLIOGRÁFICAS}

Abdelilah - Bauer, B. (2012). Le défi des enfants bilingues. Ed. La Découverte,7-9.

Al-Hoorie, A. H. \& MacIntyre, P. D. (2020). Contemporary Language Motivation Theory: 60 Years Since Gardner and Lambert (1959). Multilingual Matters.

Baker, C. Wright, W. E. (2021). Foundations of Bilingual Education and Bilingualism. 7th ed. Multilingual Matters. Boehm, A.E. (2012). Test Boehm de Conceptos básicos.3. 
Correia, L. (2017). O efeito da exposição linguística sobre a competência lexical de crianças lusodescendentes residentes na Alemanha. Tese de Mestrado em Português, língua não materna: português, língua estrangeira e português língua segunda. Universidade do Minho.

Correia, L. \& Flores, C. (2017). The Role of Input Factors in the Lexical. Development of European Portuguese as a Heritage Language in Portuguese-German Bilingual Speakers. Languages, 2 (4), 30. https://doi.org/10.3390/languages2040030

Gabriele, K. \& Bärbel, G. (2013). Training TestDaF: Material Prüfungsvorbereitung .Ed. Langenscheidt. Grosjean, F. (2021). Life as a Bilingual. Cambridge University Press.

Lundquist-Mog, A. \& Widlok, B. (2015).DLL: DaF für Kinder. Vol. 8. Ed. Ernst Klett Sprachen.

Marôco, J. (2007). Análise Estatística com utilização do SPSS. 3a ed. Eds. Sílabo.

Piaget, J. (1952). The Origins of Intelligence in Children. W.W. Norton \& Co.

Vygotsky, L. S. (1934). A construção do pensamento e da linguagem. Martins Fontes. 
